\title{
Costras de yeso responsables de la degradación de pinturas levantinas en la provincia de Teruel
}

\section{Víctor M. Orera $^{a^{\dagger}}$, Manuel Bea ${ }^{b^{*}}$, Rafael Domingo ${ }^{b}$ y Pilar Utrilla ${ }^{b}$}

${ }^{a}$ Instituto de Ciencia de Materiales de Aragón (ICMA), CSIC-Universidad de Zaragoza, Pedro Cerbuna 12, 50009, Zaragoza (España). 'Área de Prehistoria, Dpt. Ciencias de la Antigüedad, Universidad de Zaragoza. C/ Corona de Aragón 42, 50009, Zaragoza.*Miembro del Comité Nacional de ICOMOS. manubea@unizar.es, rdomingo@unizar.es, utrilla@unizar.es.

\begin{abstract}
Resumen
Recientemente se ha llevado a cabo la toma de muestras de algunos conjuntos con arte Levantino de la provincia de Teruel, dos de los cuales son analizados en el presente estudio: abrigo de Arenal de Fonseca (Maestrazgo) y Ceja de Piezarrodilla (Sierra de Albarracín). El objetivo del trabajo es conocer la composición y morfología tanto de los pigmentos (rojo, negro y blanco) como del sustrato en el que se aplicaron. Para el análisis de las muestras se ha recurrido a la microscopía óptica, espectrometría Raman, microscopía electrónica de barrido de emisión de campo (FE-SEM) y análisis de energía dispersiva de rayos $X(E D X)$. Los resultados preliminares permiten sustentar una caracterización muy diferente para soporte y pigmento así como de la propia micromorfología de las superficies.
\end{abstract}

Palabras clave: arte rupestre, Patrimonio Mundial, análisis de pigmentos, costras de yeso, conservación.

\begin{abstract}
A new sampling on different Levantine rock art sites in Teruel has been carried out recently; two of them are addressed on this study: Arenal de Fonseca (Maestrazgo mountain range) and Ceja de Piezarrodilla (Albarracin mountain range). The goal of the study is to determine the composition both of the pigments (red, black and white) and the substrate where they were applied. For the analysis of the samples it was necessary a multianalitic approach by using optic microscopy, Raman spectroscopy, Field Emission Scanning Electron Microscopy (FESEM) and Energy Dispersive X-ray (EDX). Preliminary results allow us to stand a very different characterisation for the pigments and the support as well as for the surfaces micromorphologies.
\end{abstract}

Keywords: rock art, World Heritage, pigment analysis, gypsum crusts, preservation. 


\section{Introducción}

La Comunidad de Aragón cuenta con un importante conjunto de abrigos con arte rupestre post-Paleolítico, tanto Levantino como Esquemático, muchos de los cuales forman parte del Bien denominado Arte Rupestre del Arco Mediterráneo de la Península Ibérica, declarado Patrimonio Mundial por la UNESCO en 1998 (Sanz, 2012). Entre las particularidades que caracterizan a estos conjuntos cabe destacar su ubicación en abrigos al aire libre, circunstancia que afecta directamente a la conservación y visibilidad de los conjuntos rupestres debido tanto a factores naturales biológicos (crecimiento de plantas, bacterias, líquenes, insectos...) y/o climáticos (humedad, insolación, contracción y expansión térmica, variaciones de temperatura, erosión eólica...) como antrópicos, ya sean directos (vandalismo) o indirectos (polución, lluvia ácida, incendios...) (Bea y Angás, 2014). Atendiendo a la multiplicidad de factores que determinan la conservación del arte rupestre, las costras generadas sobre las pinturas, actuando como veladuras, constituyen un campo en el que se han centrado esfuerzos orientados más a la recuperación visual de los motivos que a la caracterización compositiva de las mismas.

El presente estudio se enmarca en la línea de investigación en arte rupestre del Grupo Primeros Pobladores y Patrimonio Arqueológico (Universidad de Zaragoza) en la que se contempla el análisis y caracterización compositiva de pigmentos, soportes y costras de diversos yacimientos rupestres en Aragón, centrándonos en dos casos particulares de la provincia de Teruel: Arenal de Fonseca (Maestrazgo) y Ceja de Piezarrodilla (Sierra de Albarracín) (Fig. 1). La elección de ambos conjuntos rupestres se ha determinado por factores diferenciales tales como el soporte (caliza/arenisca) así como por la temática, estilo y color de las representaciones. El diferente contexto geográfico y ambiental también se ha considerado como un posible factor determinante en la evolución de la conservación de los pigmentos. Así pues, se analizan las costras relativamente gruesas de yeso $\left(\mathrm{CaSO}_{4} \cdot 2 \mathrm{H}_{2} \mathrm{O}\right)$ documentadas en los conjuntos levantinos referidos.

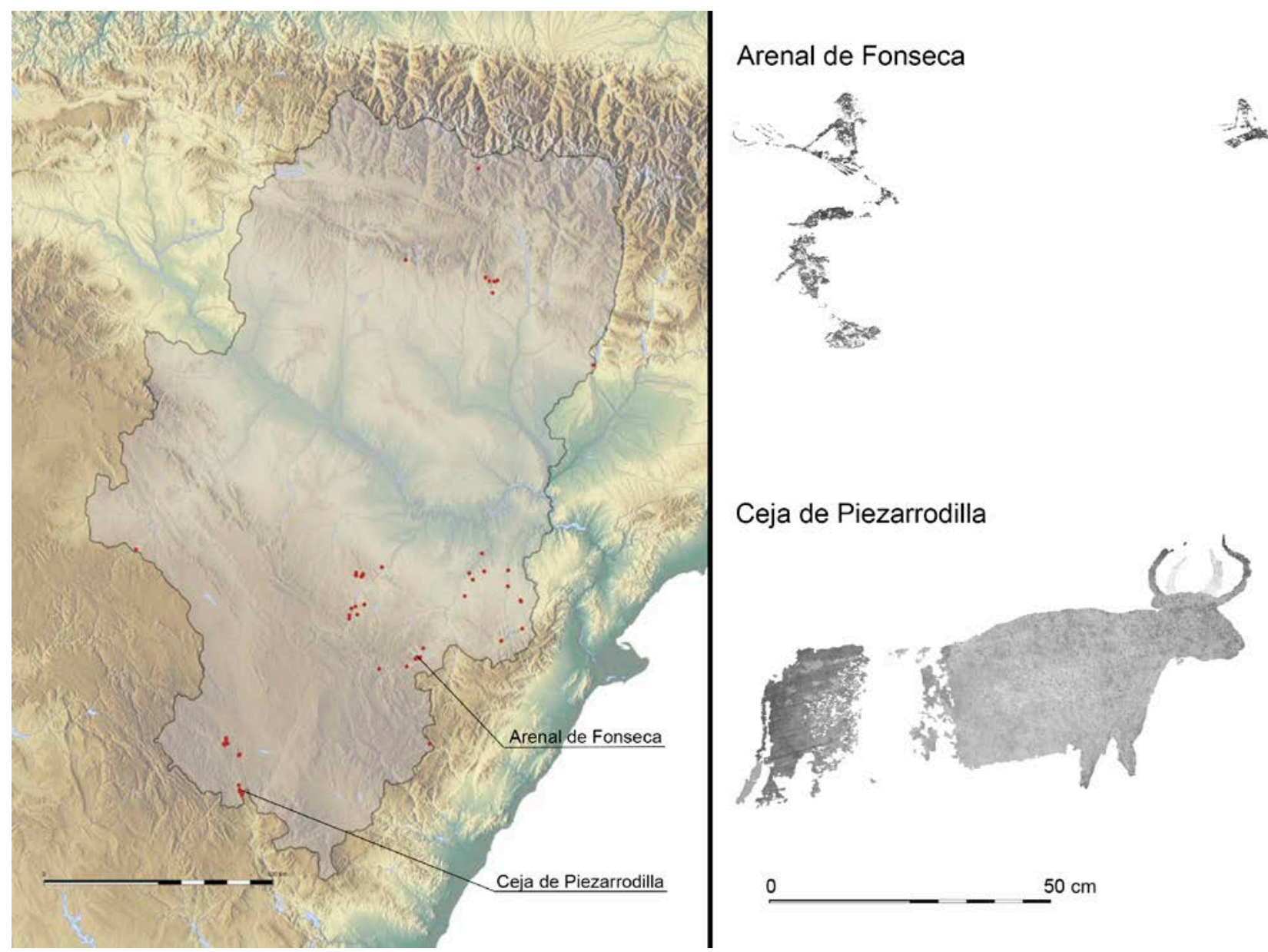

Fig. 1 Localización de los conjuntos levantinos analizados en el estudio en el contexto de abrigos Levantinos en Aragón 


\section{Metodología}

Para ambos conjuntos rupestres las muestras tomadas fueron de menos de $1 \mathrm{~mm}^{2}$ de superficie (Fig. 2), se montaron en unos soportes utilizados en las medidas de microscopía electrónica tal como han sido extraídas, sin ningún tratamiento ni procesado posterior, empleándose para su determinación técnicas de Microscopía óptica (MO), Field Emission Scanning Electron Microscope (FESEM), Energy Dispersed X-ray (EDX) y MicroRaman (mR). La morfología de las muestras a escala de decenas de micras se estudió con una lupa. La microscopía óptica y la microscopía Raman (mR) fueron utilizadas para el estudio de la microestructura y composición de las muestras. Para estos estudios se empleó un equipo Raman en geometría de backscattering acoplado a un microscopio óptico con objetivos de x5, x10, x50, x50lf y x100. El espectrómetro Raman (Modelo XY, DILOR, Lille, France) con un detector CCD trabaja con limitación de campo (pseudoconfocal). En este caso usamos excitación con laser de Ar emitiendo en el verde $(\lambda=514.5 \mathrm{~nm}$,) y con una potencia en la muestra menor de $10 \mathrm{~mW}$ para evitar el deterioro de las fases (Hanesh, 2009). Se ha medido un intervalo entre 80 y $2600 \mathrm{~cm}^{-1}$ y utilizado la línea en $520 \mathrm{~cm}^{-1}$ de un cristal de Si para calibrar las posiciones de las bandas.

La microestructura y composición de las pinturas se estudió mediante técnicas de microscopía electrónica. Las medidas de microscopía electrónica se han realizado en los servicios de apoyo a la investigación (SAI) de la Universidad de Zaragoza, en un Microscopio Electrónico de barrido de emisión de campo (FE-SEM) (Merlin, Carl Zeiss) equipado con un analizador espectroscópico de dispersión de energía (EDX) (INCA-450, Oxford Instruments). El haz de electrones tiene una energía de $15 \mathrm{kV}$ e intensidad de 600pA. El análisis elemental mediante EDX se realizó usando como patrón un cristal de Co y los estándares internos del equipo.

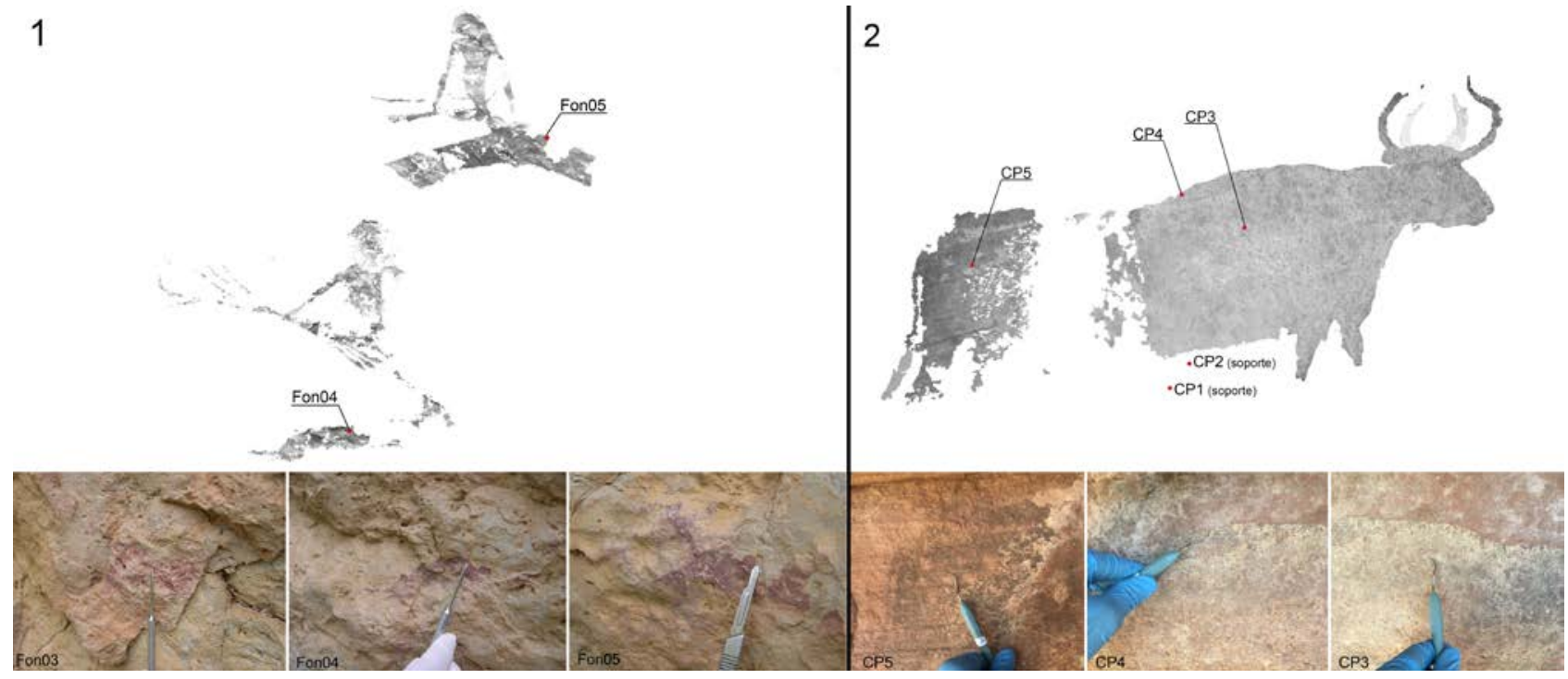

Fig. 2 Muestras tomadas en los conjuntos de 1. Arenal de Fonseca y 2. Ceja de Piezarrodilla

El análisis por EDX da a conocer la composición elemental de la muestra. Para lograr esa determinación se realizaron dos tipos de medidas: en un área extensa, aportando un valor promedio en el que se reflejan mejor las componentes mayoritarias; y un análisis puntual en zonas de aproximadamente $2 \mu \mathrm{m}^{2}$ que permite conocer la composición de un cristalito. A partir de la concentración de elementos se puede inferir, de forma aproximada, la composición de la muestra de la forma siguiente: en primer lugar decidimos cuales son los compuestos mayoritarios esperables basados en las propias medidas de EDX, mRaman y conocimientos previos. En este caso esperamos la presencia de calcita, $\mathrm{CaCO}_{3}$, cuarzo, $\mathrm{SiO}_{2}$ y feldespato (illita o moscovita), que son los componentes básicas de la roca mayoritaria de la zona. Para los ajustes se utilizó el feldespato moscovita $\mathrm{KAl}_{2}\left(\mathrm{AlSi}_{3} \mathrm{O}_{10}\right)(\mathrm{OH})_{2}$, también consideramos la presencia de yeso y anhidrita que ajustamos con la formula $\mathrm{CaSO}_{4}$, la apatita $\mathrm{Ca}_{3}\left(\mathrm{PO}_{4}\right)_{2}$ y óxidos de $\mathrm{Fe}$ y $\mathrm{Mn}$. La apatita como compuesto de P más probable y los yesos y anhidritas que han sido detectados por Raman. Luego ajustamos la concentración de los compuestos con elemento singular, por ejemplo todo el $\mathrm{S}$ se asigna al $\mathrm{CaSO}_{4}$ y todo el $\mathrm{K}$ al silicato. A partir de ahí se balancean el resto de componentes hasta llegar a una fórmula equilibrada. Por otro lado, el mRaman permite obtener 
información sobre las fases presentes en un determinado punto de la muestra. A la hora de comparar los datos obtenidos por EDX y los obtenidos por análisis mRaman hay que tener presente que el Raman que hemos realizado no es un análisis cuantitativo. Debemos tener en cuenta en las diferentes actividades Raman los defectos de cristalinidad o de estequiometría, estos últimos muy frecuentes en compuestos hidratados o presencia de luminiscencia que pueden perturbar las medidas Raman, de manera que han de tomarse como análisis meramente cualitativos.

\section{Resultados}

\subsection{Arenal de Fonseca}

El abrigo del Arenal de Fonseca (o de Ángel) se localiza muy próximo al cauce del río Guadalope en el Maestrazgo turolense, siendo uno de los 19 conjuntos rupestres con representaciones de arqueros levantinos de proporciones robustas de las piernas (paquípodo o tipo "Centelles") en el territorio. Es el único abrigo que conserva niveles de ocupación al pie de los paneles decorados que abarcan una amplia cronología, estando particularmente bien representadas fases post-Paleolíticas que van del Mesolítico de denticulados, pasando por el Mesolítico Geométrico para contar con momentos de ocupación del Neolítico antiguo y medio, algunos de los cuales presentan una interesante acumulación de restos de ocres (Utrilla et al., 2017; Orera, 2017). En los 12 metros de desarrollo del abrigo se documentan tres paneles decorados; en el Panel 3 se plasmaron las representaciones de arqueros en las que centramos nuestro análisis.

De las muestras tomadas en las unidades gráficas referidas (Fig. 2.1) las denominadas FON03, FON4 y FON05 se corresponden con pequeñas extracciones de menos de $3 \mathrm{~mm}^{2}$ de superficie con restos de pigmento. En éstas se ha determinado la existencia de eflorescencias de cristalitos de yeso $\left(\mathrm{CaSO}_{4} \cdot 2 \mathrm{H}_{2} \mathrm{O}\right)$, oxalato de calcio $\left(\mathrm{CaC}_{2} \mathrm{O}_{4} \cdot \mathrm{H}_{2} \mathrm{O}\right)$ y whewellita (w) así como nanopartículas de hematite $\left(\mathrm{Fe}_{2} \mathrm{O}_{3}\right)$ por debajo de las mismas, elementos correspondientes al pigmento (Fig. 3). El análisis FESEM permite determinar la formación de una costra de yeso de unas $8 \mu$ de espesor sobre la capa de pigmento de hematites y aporte de micas (Fig. 4).

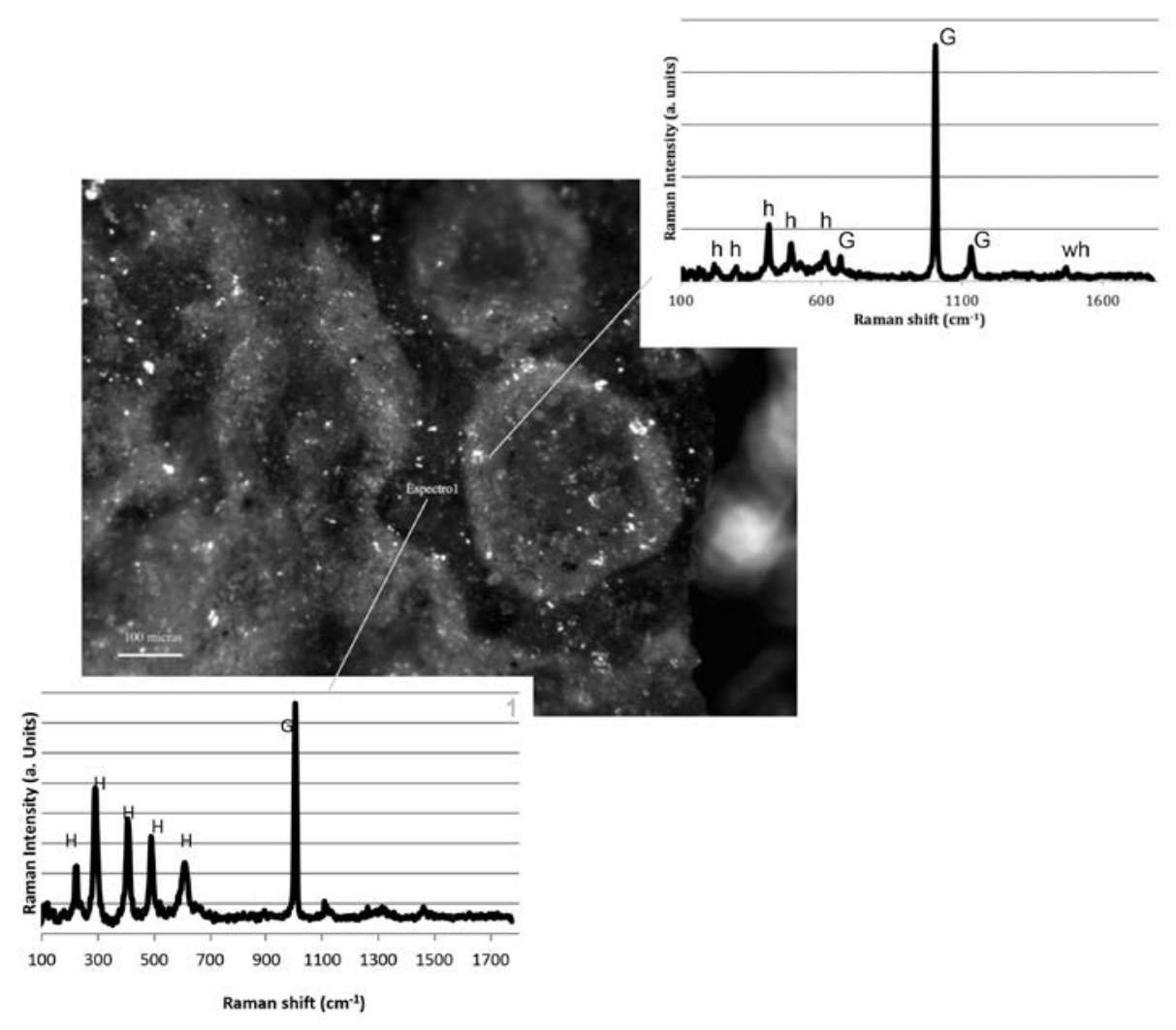

Fig. 3 Espectros Raman correspondientes sobre la muestra FON05 

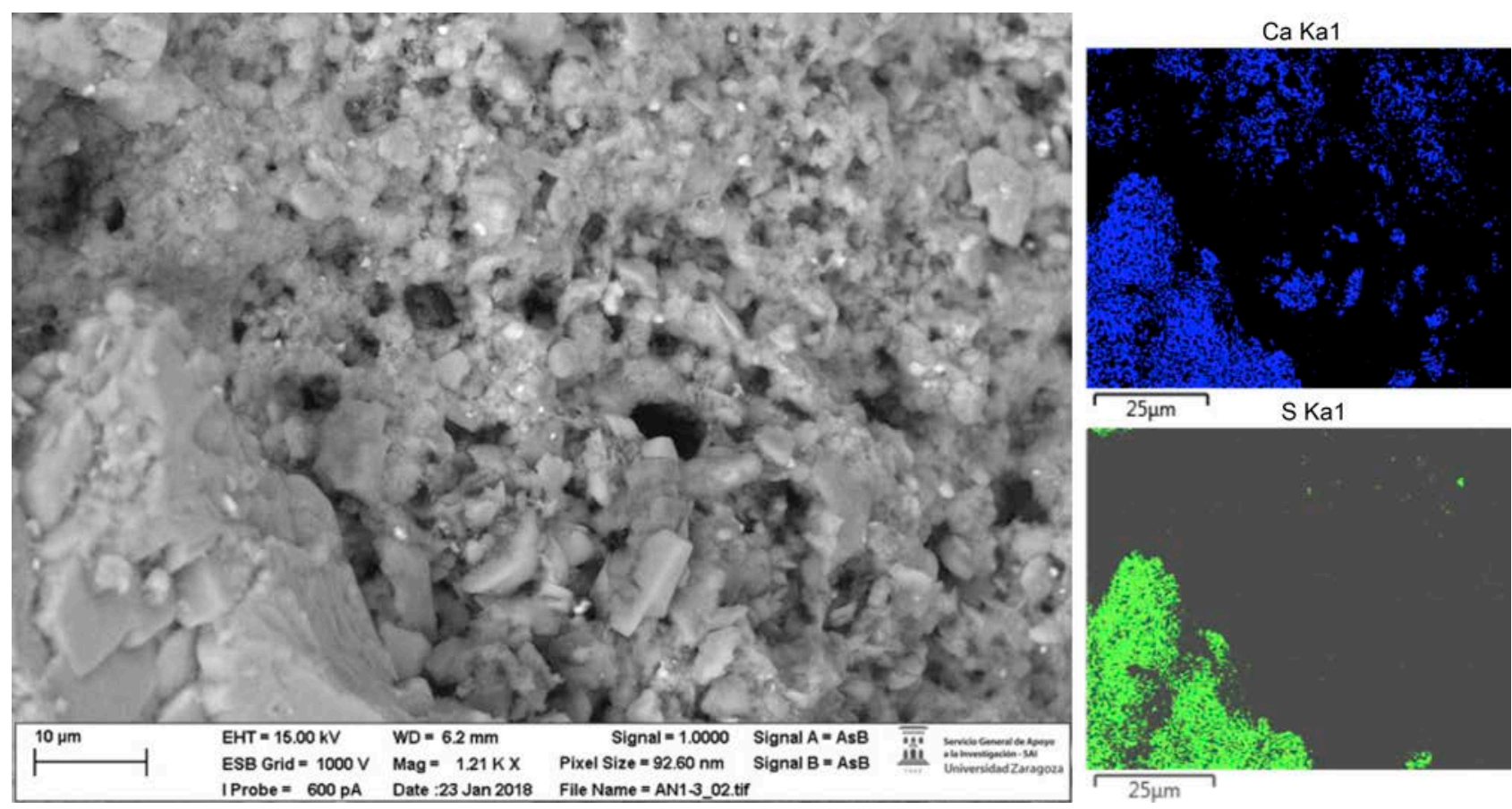

Fig. 4 Izquierda: Imagen FESEM y mapa de concentración de Ca y S. Derecha: Mapa EDS

\subsection{Ceja de Piezarrodilla}

El abrigo de la Ceja de Piezarrodilla se abre a 1267 msnm, en el denominado "Prado de Tormón" (término de Tormón, Teruel), en la parte alta de una gran formación arenisca y orientado al Sureste, contando con una visibilidad amplia sobre el entorno. De las dos representaciones pictóricas que contiene el abrigo, es la del bóvido de grandes dimensiones la más destacada y la que centra el presente estudio. Acerca del mismo, los primeros trabajos recogían la excepcionalidad del repintado en negro de un toro anterior de color blanco, identificado sólo a partir de la diferente morfología de las astas de color negro que dejan visibles las blanquecinas en la zona medial de la cabeza (Obermaier, 1927; Obermaier y Breuil, 1927). En los estudios de Piñón (1981, 1982) se hace referencia a tres fases decorativas: 1. Motivo en color blanquecino (Piñón, 1981: fig. 1a) con las astas en medialuna o perspectiva frontal; 2. Una segunda fase decorativa para la que Piñón apunta ciertos restos de tonalidad clara, ligeramente anaranjada, en distintas zonas de la mitad delantera del toro y que aparecerían debajo del pigmento negro (Piñón, 1981: fig. 1b); y 3. Una tercera fase en la que se repintaría toda la figura en color negro (Piñón, 1981: fig. 1c). Como señalamos en otros trabajos (Bea y Angás, 2015a; 2015b), las observaciones de Piñón contrastan abiertamente con las realizadas tempranamente por Obermaier y Breuil, quienes subrayaron que el color negro es "más intenso en la cabeza y en los bordes de la silueta" (1927, p. 531 y lám. xiv), precisamente las zonas en las que Piñón remarca la presencia del repintado en color claro (fig. 1b) y que, según parece, no se apreciaba en el primer estudio del conjunto. La disparidad en la definición de estos parámetros determinó el inicio de un análisis de imágenes del motivo a lo largo del tiempo, que nos permitiera conocer su evolución. Así, se consultó la documentación fotográfica del Corpus de Pintura Rupestre Levantina, llevada a cabo en 1972 por M. Almagro, constatando tan sólo dos fases decorativas. Otras referencias al motivo señalaban igualmente la existencia de dos fases decorativas, es decir, de un único repintado (negro sobre blanco) (Beltrán, 1986), refiriendo la cuidadosa superposición con la que "aunque cambiase la cronología absoluta no se alteró el estilo" (Beltrán, 1993). La consulta del fondo fotográfico llevado a cabo a finales de la década de 1980 por parte de Beltrán parecía indicar nuevamente que el color negro suponía la fase más reciente y única repintada sobre el motivo original blanco. A partir de la última campaña de documentación llevada a cabo en el conjunto, ya apuntamos la posibilidad de que "los restos anaranjados aludidos por Piñón fueran, en realidad, el componente visual de un proceso de degradación progresivo motivado, quizá, por el crecimiento de líquenes o cianobacterias, cuyos primeros procesos de crecimiento se corresponderían con la descripción realizada por Piñón y que, con el paso del tiempo, se habría ido generalizando por toda la figura" (Bea y Angás, 2015a). En la actualidad se observa una marcada diferenciación cromática en el toro con 
respecto a las imágenes consultadas de diferentes momentos. Del color negro generalizado en toda la representación observado en las fotografías de Piñón y Beltrán se pasa, en tiempos recientes, a un evidente cambio a tonalidad blanquecina sólo en la mitad delantera del motivo.

Nuestro objetivo básico ha sido tratar de analizar la pintura para deducir la composición del pigmento y determinar la existencia de elementos bióticos o minerales que afectaran a la conservación y visibilidad del motivo. Se tomaron cinco muestras (Fig. 2.2): la CP1 corresponde al sustrato rocoso, otras dos (CP3 y CP5) a distintas zonas pintadas a ambos lados de la colada calcárea, la muestra CP4 ha sido extraída del borde de la pintura y la CP2 de una zona en la que no se aprecia la pintura pero próxima a la pintura y colada. Dada la fragilidad de las muestras tratamos de evitar la posterior manipulación de las mismas y las observaciones se hicieron sobre las muestras tal como resultaron del proceso de extracción, quedando a disposición de posibles futuros estudios.

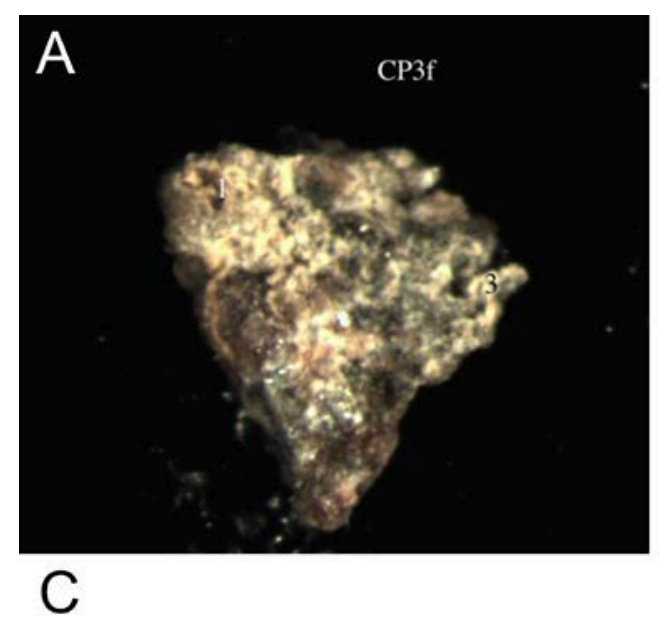
$\begin{array}{ll}\text { CP3f } 11 & 145 v s f, 193 w^{f}, 293 w^{b}, 503 w^{f}, 628 w^{f}, \\ & 1006.6 v s^{c}, 1013 s h^{c}, 1068 w^{d} \\ & 1125 m^{c}, 1341 b r^{e}\end{array}$

$3902 b r^{*}, 1006.5 b r^{c}, 1072 w^{d}, 1460.5 m^{*}$, $1485.3 \mathrm{~m}^{*}$

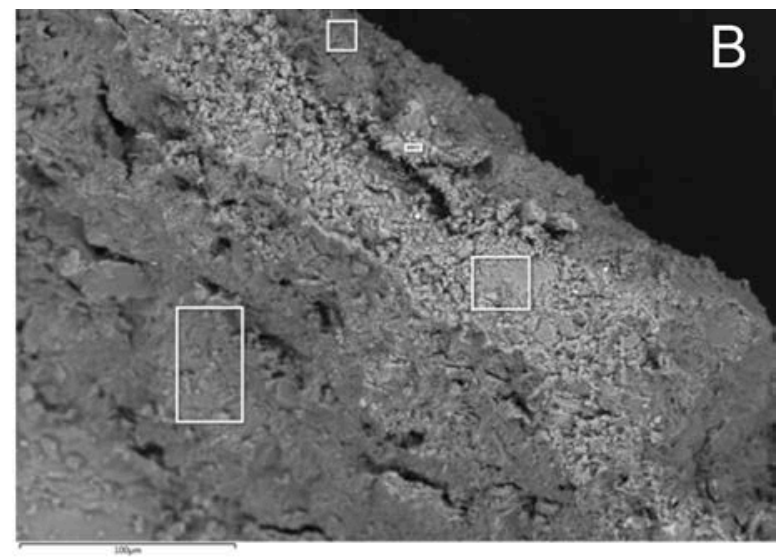

\author{
${ }^{\mathrm{b}} \mathrm{Fe}_{2} \mathrm{O}_{3}$ (hematite) \\ ${ }^{\mathrm{c}} \mathrm{CaSO}_{4}$ (Gypsum + \\ anhydrite) \\ d Carbonates \\ e Charcoal \\ f anatase \\ ${ }^{\mathrm{c}} \mathrm{CaSO}_{4}$ \\ * $\mathrm{CaC}_{2} \mathrm{O}_{4} \cdot \mathrm{H}_{2} \mathrm{O}$ (whewellite) \\ ${ }^{d}$ Carbonates
}

Fig. 5 A) Imagen óptica de cara exterior indicando sitios con análisis mRaman. B) Imagen FESEM de corte transversal con emplazamiento de zonas donde se realizaron análisis EDX. C) Análisis composicional en at\% realizado con técnica EDX de la muestra CP3f (el Carbono no ha sido cuantificado)

\section{Conclusiones}

La determinación de las composiciones de los pigmentos en el arte parietal es un problema complejo debido al deterioro de las pinturas que están realizadas al aire libre. Los efectos medioambientales que producen cambios de temperaturas, humedad, colonización por microorganismos, depósitos de polvo y acción humana al deterioro de los paneles con desconchados, formación de costras, infiltración de sales, contaminación química y biológica, etc. Por ello el procedimiento de análisis ha de ser multianalítico.

En los dos conjuntos analizados se constata un deterioro en la visualización de las pinturas, cubiertas por un velo blanquecino. Este deterioro ha ocurrido en un corto periodo de tiempo, pudiendo estar asociado a la costra de cristalitos de yeso. En el conjunto de la Ceja de Piezarrodilla la costra de yeso cubre gran parte del toro negro. El origen de las costras de yeso, de hasta $20 \mu$ de espesor, es aún incierto si bien la aparente rapidez de crecimiento pudiera indicar un origen antropogénico, seguramente asociado a la costumbre de humectar las pinturas para mejorar su visibilidad, 
intervención que podría haber acelerado un proceso natural irreversible motivado por la particular distribución de estos conjuntos rupestres en abrigos abiertos al aire libre. El yeso podría haberse incorporado bien como sal disuelta en el agua o bien por la acción de bacterias que fijan el azufre atmosférico, cuya presencia podría variar según cada yacimiento y asociarse tanto a agentes naturales como a factores antrópicos de contaminación (la central térmica de Andorra está apenas $30 \mathrm{~km}$ al NW del abrigo del Arenal de Fonseca) o incluso a la combinación de ambos.

Atendiendo a los resultados obtenidos, el bóvido de Ceja de Piezarrodilla se pintó sobre un fondo de arenisca de cuarzo y feldespato, encontrándose en la actualidad cubierto en parte por una gran colada de calcita. En la mitad delantera se observa una costra de yeso y anhidrita así como oxalatos de calcio y apatita. Asimismo, se ha podido determinar que el pigmento negro utilizado en el zoomorfo está compuesto de óxidos de manganeso, presumiblemente pirolusita y/o manganita, habiéndose detectado igualmente la presencia de carbón vegetal y óxidos de hierro (magnetita, $\mathrm{Fe}_{3} \mathrm{O}_{4}$ ) que formarían parte del pigmento negro utilizado. Los óxidos de manganeso podrían proceder de yacimientos en un entorno de unos $40 \mathrm{~km}$, de Camañas (Teruel) o también de Piqueras-Tordesilos (Guadalajara). Asimismo, se han detectado trazas de anatasa $\left(\mathrm{TiO}_{2}\right)$ en las zonas de la pintura que corresponderían a restos del pigmento con el que se pintó el toro blanco subyacente (Fig. 5). Los motivos de color blanco no son raros en la Sierra de Albarracín, si bien suponen una excepción en el conjunto Levantino peninsular. En esta línea de singularidad, se puede referir el uso de pigmento blanco constitutido por una combinación de cuarzo, anatasa, moscovita, illita y apatita en conjuntos del marco geográfico referido, Sierra de Albarracín y Sierra de las Cuercas (Cuenca) (Hernanz et al., 2008; Orera et al., 2020).

En todo caso, la presencia de anhidrita y yeso $\left(\mathrm{CaSO}_{4} \cdot \mathrm{H}_{2} \mathrm{O}\right)$ formando una costra sobre los pigmentos es un elemento bastante común en muchos conjuntos con arte rupestre al aire libre, junto a oxalatos de calcio y apatita. El origen de estas coladas de calcita (también en los casos que ocupan el presente estudio) es claramente hidrológico mientas que el yeso, oxalatos y apatitas parecen estar relacionados con la actividad biológica (microbiana) en los abrigos, seguramente potenciada por acciones antrópicas (como la humectación).

La caracterización de los pigmentos, soportes y costras asociadas a los conjuntos rupestres aparece como una línea de investigación y actuación esencial al definir con precisión los fenómenos de afectación sobre las pinturas rupestres, única vía a partir de la cual se puedan determinar protocolos de actuación presentes y futuros en relación con la conservación y preservación de un bien patrimonial tan singular y frágil como es el arte rupestre.

\section{Agradecimientos}

Las presentes líneas sirven de homenaje póstumo a la figura de Víctor M. Orera, principal artífice de los análisis contenidos en el estudio. El trabajo se enmarca en la línea de estudio y documentación integral de arte rupestre del Proyecto MINECO HAR2017-85023-P y del Grupo de Investigación Primeros Pobladores y Patrimonio Arqueológico (H14-17R) (Gobierno de Aragón y Fondo Social Europeo).

\section{Referencias}

Bea, M., y Angás, J. (2014). The conservation of Spanish Levantine Rock-Art in Aragón, Spain, using 3-D Laser Scanning. En T. Darvill y A. P. Batarda (Eds.), Open-air Rock-Art conservation and management. State of the art and future perspectives (pp. 159-166). New York: Routledge.

Bea, M., y Angás, J. (2015a). Las pinturas rupestres de Bezas y Tormón (Teruel). Teruel: Parque Cultural de Albarracín.

Bea, M., y Angás, J. (2015b). Las representaciones levantinas de bovinos de la Casa Forestal de Tormón (Teruel): Ceja de Piezarrodilla y Cerrada del Tío Jorge. Zephyrus, LXXV, 73-84.

Beltrán, A. (1986). En arte rupestre en la provincia de Teruel. Teruel, España: Instituto de Estudios Turolenses.

Beltrán, A. (1993). Arte prehistórico en Aragón. Zaragoza: Ibercaja.

Hernanz, A., Gavira-Vallejo, J. M., Ruiz, J. F., y Edwards, H. G. M. (2008). A comprehensive micro-Raman spectroscopy study of prehistoric rock paintings from Sierra de las Cuerdas, Cuenca, Spain. Journal of Raman Spectroscopy, 39(8), $972-984$. 
Obermaier, H. (1927). Nuevas pinturas rupestres descublertas en los alrededores de Tormón (Teruel). Investigación y Progreso, I(1), $1-2$.

Obermaier, H., y Breuil, H. (1927). Las pinturas rupestres de los alrededores de Tormón (Teruel). Boletín de la Real Academia de la Historia, 90, 511-531.

Orera, V. M. (2017). Estudio de pigmentos y ocres en el Arenal de Fonseca. En P. Utrilla, R. Domingo y M. Bea (Dirs.), El Arenal de Fonseca (Castellote, Teruel). Ocupaciones prehistóricas del Gravetiense al Neolítico (pp. 235-242). Zaragoza: Universidad de Zaragoza.

Orera, V. M., Bea, M., Peña-Monné, J. L., y Utrilla, P. (2020). Análisis de pigmentos del abrigo de Cabras Blancas (Tormón, Teruel). En J. I. Lorenzo y J. M. Rodanés (Eds.), Actas del III Congreso de Arqueología y Patrimonio Aragonés (pp. 73-81). Zaragoza: Ilustre Colegio de Doctores y Licenciados en Filosofía y Letras y en Ciencias de Aragón.

Piñón, F. (1981). Superposiciones y repintados en la Serranía de Albarracín: elementos para el establecimiento de una cronología relativa. En M. Almagro (Dir.), Altamira Symposium (pp. 411-425). Madrid: Ministerio de Cultura.

Piñón, F. (1982). Las pinturas rupestres de Albarracín (Teruel). Madrid: Monografías del Centro de Investigación y Museo de Altamira, 6. Ministerio de Cultura.

Sanz, N. (2012). Rock art and UNESCO World Heritage List. En J. McDonald y P. Verth (Eds.), A companion to rock art (pp. 491 514). Chichester: Wiley-Blackwell.

Utrilla, P., Domingo, R., y Bea, M. (2017). El Arenal de Fonseca (Castellote, Tearuel). Ocupaciones prehistóricas del Gravetiense al Neolítico. Zaragoza: Universidad de Zaragoza. 